\title{
As placas de xisto gravadas (e os baculos) do sitio do Monte da Barca (Coruche)
}

\section{Charles-Tanguy Le Roux}

\section{Q OpenEdition}

12 Journals

Édition électronique

URL : https://journals.openedition.org/rao/1868

DOI : 10.4000/rao.1868

ISBN : 978-2-7535-2790-4

ISSN : $1775-3732$

Éditeur

Presses universitaires de Rennes

Édition imprimée

Date de publication : 30 décembre 2012

Pagination : 321

ISBN : 978-2-7535-2641-9

ISSN : 0767-709X

\section{Référence électronique}

Charles-Tanguy Le Roux, «As placas de xisto gravadas (e os baculos) do sitio do Monte da Barca

(Coruche) », Revue archéologique de l'Ouest [En ligne], 29 | 2012, mis en ligne le 30 décembre 2012, consulté le 30 juillet 2021. URL : http://journals.openedition.org/rao/1868 ; DOI : https://doi.org/ $10.4000 /$ rao. 1868

Ce document a été généré automatiquement le 30 juillet 2021.

@ Presses universitaires de Rennes 


\title{
As placas de xisto gravadas (e os baculos) do sitio do Monte da Barca (Coruche)
}

\author{
Charles-Tanguy Le Roux
}

\section{RÉFÉRENCE}

Gonçalves V. S., 2010 - As placas de xisto gravadas (e os baculos) do sitio do Monte da Barca (Coruche), Lisbonne, Centro de Arqueologia da universidade de Lisboa (cuadernos da UNIARQ, 7), 184 p. (ISBN 978-989-95653-5-7).

1 En 1971, des terrassements liés aux aménagements d'une coopérative agricole mirent au jour un remarquable ensemble de plaques et de crosses gravées en schiste. La découverte survint à $20 \mathrm{~km}$ à l'est de Lisbonne et $8 \mathrm{~km}$ au sud du Tage, en bordure sud de la plaine alluviale de la rivière Soria, face au bourg de Coruche et non loin d'un camp chalcolithique bien connu pour avoir abrité une fabrique de telles plaques. Les conditions dans lesquelles deux amateurs purent recueillir ce matériel furent des plus précaires mais aucune structure mégalithique, même sommaire, ne semble lui avoir été associé. Les inventeurs présentèrent sommairement cette découverte au 3e coloquio nacional de Arqueologia en 1973, puis une publication préliminaire s'ensuivit en 1974 avant que l'oubli ne fasse son œuvre. Le matériel aujourd'hui conservé au musée de Coruche comprend 29 plaques et 3 crosses, plus quelques éléments lithiques et céramiques.

2 C'est dans le cadre des programmes Placa nostra et Ansor lancés par l'UNIARQ que l'auteur a été amené à reprendre en 2009 l'étude de cet ensemble exceptionnel par son effectif et sa qualité, bien qu'il concerne des objets classiques du Chalcolithique ouestibérique. Point n'est besoin de présenter le professeur V. S. Gonçalves, fondateur de ce centre d'archéologie de l'université de Lisbonne qu'il dirige avec brio. Sa personnalité 
aux multiples facettes transparaît dans la présentation - moderne et soignée, parfois un brin déjantée mais toujours rigoureuse - du volume qu'il nous propose.

3 Après une mise en contexte circonstancielle de cette découverte, le corpus est méthodiquement et minutieusement décrit, classé et interprété avec force dessins d'une grande précision et de somptueuses photographies. Tous les éléments de comparaison sont passés en revue : les trop rares artefacts directement associés à cette découverte et les autres plaques et crosses connues régionalement avant d'évoquer des parallèles plus lointains (de l'Égypte pharaonique aux dolmens armoricains). En ce qui concerne le calage chronologique, les données vraiment pertinentes restent rares; l'auteur reste donc sur la fourchette communément admise de la toute fin du -IVe millénaire au début du-IIIe.

4 Nous n'aurons pas grand-chose à ajouter à l'argumentaire présenté en ce qui concerne les plaques; pour les « crosses », remarquons cependant deux choses :

5 - Tout d'abord, l'évocation (rapide il est vrai) des pétroglyphes armoricains aurait pu mieux souligner le décalage chronologique (plus d'un millénaire d'antériorité par rapport aux crosses ibériques) et les inévitables aléas inhérents à tout rapprochement d'objets réels (quels qu'ils soient) avec leurs supposées représentations ;

6 - Ensuite, deux types d'artefacts ne seraient-ils pas indûment mêlés dans la discussion? Les crosses égyptiennes sont - à juste titre - rapprochées des bâtons de commandement ou des masses d'armes qui les auraient précédées. Mais les uns et les autres sont des objets élancés et à section quasi-isométrique ; c'est loin d'être le cas des "crosses" ibériques, trop rarement représentées de profil ou en coupe dans la littérature (ici, ce n'est le cas que pour une des trois pièces mais la figure 3.3 est révélatrice de cet extrême aplatissement). Certes, le mot boomerang est lâché dans la discussion, mais uniquement pour évoquer - sans le nommer mais cela semble transparent dans l'esprit de l'auteur - le célèbre «dieu à la faucille» hongrois de Szegvar-Tüzköes. Référence aurait pu être faite aux «bâtons de jet » attestés dans les stations palafittiques et récemment rapprochés des «crosses » de l'art mégalithique armoricain par S. Cassen. Parmi les parallèles possibles, n'oublions pas non plus le lagobolon de la Grèce archaïque, cette arme de jet destinée à une chasse au lièvre initiatique au sortir de l'adolescence. Resterait à un lanceur expert à tester dans quelle mesure une «crosse » de type portugais (en schiste ou en bois) pourrait se comporter comme un boomerang - ou du moins comme un frisbee!

7 En résumé, nous avons là un "beau livre ", qui certes ne concerne qu'à la marge la préhistoire de l'ouest de la France, mais qui combine fantaisie, luxueuse présentation, et rigueur du fond (ce qui n'est pas si commun). Il s'achève par une bibliographie fouillée (un brin narcissique cependant : 67 entrées « Gonçalves » sur 110 références) et par un résumé bilingue (portugais/anglais) que l'on aurait souhaité un peu plus développé. Tout néolithicien (et au-delà tout préhistorien tant soit peu esthète - il y en a) aimera détenir et compulser cet ouvrage. 